University of Wollongong

Research Online

$1-1-2016$

\title{
Shaping pathways to gambling consumption? An analysis of the promotion of gambling and non-gambling activities from gambling venues
}

Amy Bestman

University of Wollongong, aeb463@uowmail.edu.au

Samantha L. Thomas

University of Wollongong, slthomas@uow.edu.au

Melanie J. Randle

University of Wollongong, mrandle@uow.edu.au

Hannah Pitt

University of Wollongong, hlp674@uowmail.edu.au

Mike Daube

Curtin University, m.daube@curtin.edu.au

See next page for additional authors

Follow this and additional works at: https://ro.uow.edu.au/ahsri

Research Online is the open access institutional repository for the University of Wollongong. For further information contact the UOW Library: research-pubs@uow.edu.au 


\title{
Shaping pathways to gambling consumption? An analysis of the promotion of gambling and non-gambling activities from gambling venues
}

\author{
Abstract \\ Background: In Australia, venues which provide gambling activities also provide activities that are utilised \\ by families and children. However, there has been limited theoretical or empirical discussion about \\ whether engagement with non-gambling activities may play a role in shaping pathways to current or \\ future engagement in gambling within these environments. We examined marketing tactics for non- \\ gambling and gambling activities in Clubs. Using this data, we propose a conceptual model to test the \\ role of non-gambling activities within gambling environments in shaping gambling attitudes and \\ consumption intentions. Methods: This study used a mixed method interpretive content analysis to \\ review the marketing activities on the websites of a sample of 65 registered Clubs in New South Wales, \\ Australia. We identified the extent and nature of techniques used to market gambling and non-gambling \\ activities, particularly non-gambling activities directed towards families and children. Results: Clubs use \\ various marketing tactics to appeal to families and encourage parents to bring their children into venues. \\ We hypothesise that marketing aimed at bringing children and families into gambling environments may \\ play a role in shaping children's and adults perceptions of these environments and may be influential in \\ the development of a pathway that increases the likelihood that children will continue to visit these \\ environments as adults, and subsequently the extent to which they engage in gambling later in life. \\ Conclusions: Future research should explore how the presence of family-friendly activities in Clubs and \\ other venues with gambling activities may play a role in shaping future gambling attitudes and \\ behaviours.
}

\section{Publication Details}

A. Bestman, S. Thomas, M. Randle, H. Pitt, M. Daube \& S. Pettigrew, "Shaping pathways to gambling consumption? An analysis of the promotion of gambling and non-gambling activities from gambling venues", Addiction Research and Theory 242 (2016) 152-162.

\section{Authors}

Amy Bestman, Samantha L. Thomas, Melanie J. Randle, Hannah Pitt, Mike Daube, and Simone Pettigrew 


\section{Shaping pathways to gambling consumption? An analysis of the promotion of gambling and non-gambling activities from gambling venues.}

Amy Bestman, PhD Student, School of Health and Society, Faculty of Social Sciences, University of Wollongong.

Samantha Thomas, Principal Research Fellow, School of Health and Society, Faculty of Social Sciences, and Australian Health Services Research Institute, Faculty of Business, University of Wollongong.

Melanie Randle, Associate Professor of Marketing, School of Management, Operations and Marketing, Australian Health Services Research Institute, Faculty of Business, University of Wollongong.

Hannah Pitt, Research Assistant, School of Health and Society, Faculty of Social Sciences, University of Wollongong.

Mike Daube, Professor of Health Policy, Curtin University.

Simone Pettigrew, Research Professor, School of Psychology and Speech Pathology, Curtin University, and Director, WA Cancer Prevention Research Unit (WACPRU).

Corresponding Author: Amy Bestman, School of Health and Society, Faculty of Social Sciences, and Australian Health Services Research Institute, Faculty of Business, University of Wollongong. amybe@uow.edu.au 


\section{Abstract}

\section{Background:}

In Australia, venues which provide gambling activities also provide activities that are utilised by families and children. However, there has been limited theoretical or empirical discussion about whether engagement with non-gambling activities may play a role in shaping pathways to current or future engagement in gambling within these environments. We aimed to examine the marketing tactics for non-gambling and gambling activities in Clubs. We use this data to propose a conceptual model to test the role of non-gambling activities within gambling environments in shaping gambling attitudes and consumption intentions.

\section{Methods:}

This study used a mixed method interpretive content analysis to review the marketing activities on the websites of a sample of 65 registered Clubs in regional New South Wales, Australia. We used a coding framework to identify the extent and nature of techniques used to market gambling and non-gambling activities. We particularly focused on non-gambling activities directed towards families and children.

\section{Results:}

Whilst Clubs heavily promote gambling activities on their websites, there is also a strong presence of content that promotes Clubs as family venues. We hypothesise that marketing strategies aimed at bringing children and families into environments that feature gambling 
products may play a role in shaping children's and adults' perceptions of these environments, and be influential in the development of a pathway that increases the likelihood that children will continue to visit these environments as adults, which subsequently may influence the extent to which they engage in gambling later in life.

\section{Conclusions:}

Clubs use various marketing tactics to appeal to families and encourage parents to bring their children into gambling venues. Future research should explore how the presence of familyfriendly activities in Clubs and other venues with gambling activities may play a role in shaping future gambling attitudes and behaviours.

\section{Keywords:}

Gambling; Children; Gambling Attitudes; Gambling Behaviours; Public Health; Pathways.

Word Count: 4350 


\section{Introduction}

\subsection{Problem gambling in Australia}

Australia is reported to be the gambling capital of the world (The Economist, 2014). According to the Australian Productivity Commission Report, around \$19 billion dollars was spent on gambling in Australia in 2008/9 (Australian Productivity Commission, 2010). Defined as "difficulties in limiting money and/or time spent on gambling that leads to adverse consequences for the gambler, others, or for the community" (Neal, Delfabbro, \& O’Neil, 2005, p. 109), problem gambling is experienced by approximately 80,000 to 160,000 Australians (about 1.4\% of the community) every year (Australian Productivity Commission, 1999, 2010). Research shows that the individual and social harms associated with problem gambling are significant, and include criminality (Walters, 1997), relationship problems and family violence (Kalischuk, 2010; Kalischuk, Nowatzki, Cardwell, Klein, \& Solowoniuk, 2009; Suomi et al., 2013; Salonen, Castrén, Alho, \& Lahti, 2014; Svensson, Romild, \& Shepherdson, 2013; Wenzel, Øren, \& Bakken, 2008), and psychological harms (e.g. mental health problems, substance use disorders and suicide) (deCastella, Bolding, Lee, Cosic, \& Kulkarni, 2011; Holdsworth, Haw, \& Hing, 2012; Lorains, Cowlishaw, \& Thomas, 2011). It is estimated that for every person who develops a problem with gambling, approximately 510 other individuals are impacted, including family members, friends and employers (Australian Productivity Commission, 2010). While significant research has focused on the role of individual pathology in the manifestation of problem gambling (Blaszczynski, Ladouceur, \& Shaffer, 2004), much less has focused on industry tactics (Thomas, Lewis, McLeod, \& Haycock, 2012), product designs (Dow-Schüll, 2012), and gambling environments (e.g. the clustering of gambling products and marketing for these products in 
specific environments) (Lindsay et al., 2013; Young, Markham, \& Doran, 2012a). We know of no research to date that comprehensively considers how these factors work both independently and together to create and perpetuate problem gambling in communities.

\subsection{Electronic Gaming Machines}

While Australian adults (aged 18 years and over) are able to gamble using a range of different goods and services (such as lotteries, wagering services and casino games), it has been suggested that Australia's gambling problems thus far have been primarily linked to industry and government reliance on the revenue from a specific gambling product - Electronic Gaming Machines (EGMs) (Australian Productivity Commission, 2010). These devise are more commonly known as 'pokies', ‘poker machines' and 'slots'. In 2008-9, Australians spent about $\$ 10.5$ billion on EGMs, representing 55\% of total gambling expenditure (Australian Productivity Commission, 2010, Roy Morgan, 2014). EGMs are designed to make profits for organisations, which by definition means that the people who play them must lose more money than they win. This is explicitly acknowledged in documentation from the Gaming Technology Association, the peak body for EGMs in Australia:

It is important to understand that these machines are NOT designed to make you money on any regular or long-term basis. Winning sessions may occur but you should expect that the long term outcome will be to lose money - otherwise the venue that provides you the opportunity to play could not afford to keep the machines! (Gaming Technologies Australia, 2015, p. 2) 
EGMs are also the product most commonly associated with problem gambling (Storer, Abbott, \& Stubbs, 2009), reflecting both their design and accessibility (Australian Productivity Commission, 2010). EGMs are clustered in areas of socio-economic disadvantage, with higher annual expenditure in poorer areas (Doran, McMillen, \& Marshall, 2007; Robitaille \& Herjean, 2008; Young, Markham, \& Doran, 2012b), thus placing a disproportionate burden of harm on some of the most vulnerable communities.

\subsection{Electronic Gaming Machine Environments: The Role of Clubs}

In Australia, most EGMs are located in registered Clubs (61\%), with smaller proportions located in hotels (pubs) and casinos (Australian Productivity Commission, 1999a). In New South Wales (NSW), up to three quarters of EGMs are located in Clubs (Hing, 2006). Clubs are defined as "not-for-profit community-based organisations whose purpose is to provide infrastructure and services for the community” (Clubs Australia, 2015a). There are several types of registered Clubs including Sports Clubs (such as tennis, bowling, fisherman's or leagues Clubs) and Returned Servicemen's League (RSL) Clubs. Clubs Australia state that they contribute to their local communities "through employment, cash and in-kind social contributions, and through the formation of social capital by mobilising volunteers and providing a diverse and affordable range of services, facilities and goods" (Clubs Australia, 2015b). Despite these stated social and community objectives, researchers have highlighted that Clubs have become particularly dependent on the "aggressive pursuit" of revenue from EGMs for their financial survival (Hing, 2006, p. 85). It is therefore unsurprising that Clubs in Australia have actively opposed some reform proposals aimed at preventing the harm associated with EGMs which may impact on the profits they make from these machines (Miller, Thomas, Robinson, \& Daube, 2014). 
In NSW it is legal for individuals aged younger than 18 years to attend Clubs. However the areas where minors are allowed to be present are restricted, for example minors cannot be in designated gaming areas where EGMs are present (NSW Government, 1976). Clubs provide services not solely used by adults - they also offer a range of activities and product offerings for families and children. These include children's holiday programs, playgrounds, babysitting services, games rooms, and restaurant incentives to encourage family dining, including cheaper children's meals. Most recently, there has been a proposal for “Clubs, as NFP (Not for Profit) member-based community organisations with significant revenue from hospitality and gaming, already work with governments at all levels and community groups to identify, fund and deliver affordable social services”, including for older adults and children (McKell Institute, 2014, p. 6). While there has been some peripheral discussion about the tension between Clubs as environments that provide both family activities and gambling activities (Needham, 2014; Nowell, 2009), there appears to be a lack of research that systematically documents the extent and nature of these promotional activities.

Previous research has clearly identified that children are important future customers for dangerous consumption industries (Hammond \& Rowell, 2001; Ling \& Glantz, 2002), as exemplified by tobacco company statements such as “today's teenager is tomorrow's potential regular customer” (Hammond \& Rowell, 2001, p. 33). What is less clear is whether there are behavioural conditioning mechanisms (such as marketing techniques) that soften community attitudes to gambling venues, thereby potentially influencing the consumption of gambling products and services.

\subsection{How can marketing shape unhealthy product consumption?}


In order to understand the short- and long-term influences of commercial environments on children, it is important to understand the role that marketing plays in conditioning consumer behaviours. Nord and Peter (Nord \& Peter, 1980; Peter \& Nord, 1982) developed the behaviour modification perspective (BMP), which acknowledges the role of internal psychological processes that influence behaviour while also focusing on the environmental and contextual factors that affect consumer behaviour. Shaping is one marketing technique that encourages behavioural learning incrementally in a series of sequential and intermediate steps that progress towards a desired behaviour (Nord \& Peter, 1980; Peter \& Nord, 1982). Consumers are encouraged to perform one behaviour with the ultimate aim of having them perform another, different behaviour - for example, gambling venues offer free children's activities to attract families to the venue, and subsequently parents may participate in gambling activities. The strategy encourages one behaviour (a: bringing children along to participate in the free activities), which then leads to a subsequent behaviour (b: parents entering the venue), and may ultimately lead to another different behaviour (c: parents gambling in the venue). In some respects this strategy may be viewed as covert because the ultimate behaviour may not be obvious to consumers as they are only explicitly encouraged to perform the first initial behaviour in the sequence, and the subsequent behaviours are only implicitly encouraged (Martin \& Smith, 2008).

Shaping can be particularly effective when the desired behaviour is complex or represents a significant departure from existing behaviours (Rothschild \& Gaidis, 1981). This is often the case in social marketing where the objective of marketers is to positively influence consumers' attitudes and behaviours to improve their personal welfare or that of society as a whole (Webster, Carter, D'Alessandro, \& Gray, 2013). Whilst this strategy has been used 
effectively for public health campaigns like those to improve eating and exercise habits, decrease road trauma or encourage individuals to quit smoking, there is also evidence that commercial organisations have used shaping techniques to indirectly encourage harmful behaviours amongst vulnerable populations. For example, it has been suggested that producers of adult-only products (alcohol and tobacco) may indirectly target children through a range of strategies that include alignment with sports stars and celebrities, promotion within specific environments such as sporting games and the sponsorship of activities with which children are associated (ANHPA, 2014; Lindsay et al., 2013; Ling \& Glantz, 2002).

Marketing plays an important role in shaping new cultural rituals and patterns of consumption. While it is generally thought that advertising (as one form of marketing) influences the ritual behaviours that lead to the consumption of various goods and services (Halford, Gillespie, Brown, Pontin, \& Dovey, 2004; Smith \& Foxcroft, 2009), there is some discordance in the literature about how this occurs. For example, McCracken (1986) suggests that advertising has a direct one-way influence on patterns of possession, exchange, grooming and divestment, while others argue that there is a mutual two-way process in which marketers use advertising to link their products with existing cultural rituals and practices by investing them with the meanings associated with those practices (Otnes \& Scott, 1996; Sherry, 1987).

To our knowledge, researchers have not examined how marketing is used to actively attach cultural meanings and rituals to activities that are valued by families and children within gambling environments, or how this in turn may shape their longer-term engagement in the gambling activities that co-exist within these environments. 
This exploratory study sought to determine the extent and nature of family-friendly activities and gambling activities promoted using a specific sample of NSW registered Clubs' websites. We used this information to hypothesise how the promotion of these activities may play a role in shaping community attitudes and behaviours within environments that contain familyfriendly activities and gambling facilities. We propose a conceptual model that may be used to guide future research in this area.

\section{Methods}

\subsection{Approach and sampling strategy}

We conducted an interpretive web-based content analysis of a sample of Clubs in a specific area of regional New South Wales, Australia. The regional area analysed was located outside of Sydney with a population of approximately 200,000 residents. Two researchers reviewed each Club to ensure that they had a dedicated website with multiple pages. Ten Clubs did not meet this criterion and were excluded from the sample, leaving a usable sample size of 68 Club websites. For each Club website used in the analysis, we confirmed whether the venue contained Electronic Gaming Machines, either through reviewing annual reports (on website) or calling the Club directly. From this we ascertained that three Clubs did not have EGMs, leaving a total sample of 65.

\subsection{Data collection}

We collected information about the location, size (as measured by membership numbers) and EGM revenue of Clubs. The suburb in which the Club was located (as stated on the Clubs 
NSW website) was mapped to Socio-Economic Indicators for Areas Index of Relative Social Advantage and Disadvantage (SEIFA) classifications (a suburb-level measure of socioeconomic advantage and disadvantage from 1 , the most disadvantaged, to 10 , the most advantaged) (ABS, 2013). Where available, data relating to the size and EGM revenue of Clubs were collected from information contained in the Clubs’ Annual Reports as published on their websites.

The constant comparative method was used to analyse the data (Glaser \& Strauss, 1967), and a coding list was subsequently developed to categorise the information contained on the Clubs' websites. Initially, we looked for marketing information relating to activities for families, children or gambling. This involved reviewing all pages on the websites and developing first-order categories (grouping data based on individual types of marketing content, for example offering children's play equipment) which, through an iterative process, were then grouped into second-order categories (grouping the data into broader categories, for example categories relating to children's activities more generally) (Rossiter, 2011). Data were recorded as appearing on either the website home page - the primary page viewed when accessing the Club website, or on secondary pages - additional webpages within the Club website. The categories and their associated definitions (presented in Table 1) were separated into content relating to families or children and gambling-related content. These were then used by two independent researchers to identify and code data during March 2014. The coded data were cross-checked by the two researchers, thus ensuring inter-rater reliability (Armstrong, Gosling, Weinman, \& Marteau, 1997).

Information was recorded for websites' home pages and secondary pages. All of the website pages were printed by the researchers as a permanent record of their content because sites are updated regularly and the information changes. The printed pages were also used as a point of 
reference in case any discrepancies were identified between coder ratings, however no significant discrepancies were found.

\subsection{Data Analysis}

Website data were entered into SPSS version 19. In order to assess the extent to which Clubs' websites were targeting children and families, frequency counts were performed for the home page and secondary pages to identify the percentage of Clubs' websites that included information that could be classified into the family and children categories listed in Table 1 . Frequency counts were also used to determine the extent of gambling marketing throughout Clubs' websites and were classified into the gambling categories listed in Table 1. Qualitative data were analysed using thematic techniques (Miles \& Huberman, 1994).

\section{Results}

\subsection{Sample characteristics}

Table 2 provides information about the characteristics of the (census) sample of Clubs with EGMs in the specific regional area studied. Of the 65 Clubs in the sample, the largest proportion were bowling Clubs ( $n=25,39 \%)$, followed by Returned Servicemen's League Clubs ( $\mathrm{n}=11,17 \%)$, and football Clubs (12\%). Golf Clubs and generic sports Clubs made up small proportions of the sample ( $n=5,8 \%$ and $n=4,6 \%$ respectively). The remaining 12 Clubs (19\% of the sample) were grouped into an "other" category and included a tennis Club, a workers’ Club, culture-specific Clubs, a fishermens’ Club and a boating Club. 
Nearly two-thirds of the Clubs ( $n=39,60 \%)$ were geographically located in the bottom three socio-economic deciles (SEIFA scores 1-3), 17 Clubs (26\%) were located in the mid-range deciles (SEIFA scores 4-7) and 9 Clubs (14\%) were located in the top three deciles (SEIFA scores 8-10). No Clubs were located in geographic areas ranked in the top decile (SEIFA score 10).

Of the 49 Clubs that provided an annual report on their website, one third reported having between 1,000-5,000 members ( $n=17,35 \%), 10$ percent $(n=5)$ had between 5,000-10,000 members and 14 percent had 10,000 members or more. Only six percent of the sample $(n=3)$ reported having fewer than 1,000 members, however over one-third of Clubs for which annual reports were available ( $\mathrm{n}=17,35 \%)$ did not report membership numbers.

Finally, in terms of the gross revenue obtained through EGMs, almost one third of Clubs with annual reports ( $n=16,33 \%$ ) reported revenue of $\$ 1$ million or less from EGMs, 15 Clubs (31\%) reported revenue of between \$1-5 million, nine Clubs (18\%) obtained between \$5-10 million from EGMs, while a further six Clubs (12\%) reported revenue from EGMs of $\$ 10$ million or more. Three Clubs did not disclose the gross revenue from EGMs in their annual report.

\subsection{Extent and nature of marketing activities targeting families and children}

Table 3 summarises the range of marketing strategies used by Clubs to attract families and children, as well as the total percentage of Clubs that promote such activities on their home and secondary pages (percentage values are indicated in parentheses). One in five websites $(n=13,20 \%)$ included family-related information on their home page. However, when 
secondary web pages were also considered, the majority of Clubs ( $n=56,86 \%$ ) promoted goods or services that specifically appealed to families with children.

Of the Clubs that promoted activities or products for children and families on their home page, the most commonly used strategy was text that explicitly invited parents to bring their family to the Club $(n=6,9 \%)$. This was followed by dining promotions tailored for children, such as receiving free meals when accompanying a paying adult or offering customised menu items for children $(n=4,6 \%)$. A broader range of promotional strategies targeting families and children appeared on secondary webpages, including dining promotions aimed at children ( $n=45,69 \%)$; activities to entertain children whilst at the Club, for example under 18s’ discos, Kids' Clubs or play equipment ( $n=14,22 \%)$; supervised child-minding services ( $n=6,9 \%)$; promotions associated with seasonal events or school holidays ( $n=9,14 \%)$; family days with free food and rides $(n=4,6 \%)$; and competitions with family-based prizes (e.g. a holiday for two adults and two children to Disneyland) (n=3, 5\%). Finally, a number of Clubs promoted miscellaneous services aimed at children $(n=11,17 \%)$, which included sports and games (e.g. mini-golf or lawn bowls), children's priced tickets for live entertainment, i.e. “Kids” Clubs” and magic shows.

Qualitative analysis of material presented on the websites clustered into three distinct themes. The first theme to emerge related to the Club being a 'friendly', 'safe', and 'fun' environment for children and families. This was represented through a variety of activities directly targeting children. For example, Kids' Club promotions offered "free monthly kids' activities, and a fun welcome pack when you join”. Many Clubs also offered regular weekly meal specials, including a “Sunday family feast $\$ 49$ ”. The second theme related to how the Clubs help families celebrate holidays and valued social rituals. For example, promoting children’s parties such as “Kids Junior Groovers Disco - book your next kids disco party 
with us for only $\$ 12$ per child”. The third theme related to the Club having an important broader role in the community, with taglines such as "supporting our local community" appearing on a number of websites. Other examples included "supporting local sport" via raffles on regular weeknights where "all proceeds go back to the community".

\subsection{Extent and type of gambling promotions}

$\underline{\text { Table } 3}$ illustrates the frequency and types of gambling-related promotions on Clubs' websites. Forty Clubs (62\%) included gambling information on their home pages, which most commonly included promotions for raffles ( $n=30,46 \%)$, TAB facilities $(n=17,26 \%)$ and Keno $(n=16,25 \%)$. A similar pattern was found when secondary pages were examined, although the percentage of Clubs that included the information was greater, with 61 of the 65 Clubs (94\%) promoting gambling on their secondary pages. About three-quarters of Clubs promoted raffles on their secondary pages $(n=51,79 \%)$, about two-thirds promoted TAB facilities ( $n=44,68 \%)$, over half promoted Keno ( $n=36,55 \%), 26(n=40 \%)$ promoted cash poker and nine Clubs (14\%) provided information about dedicated gaming areas. 'Other' gambling promotions included a losing TAB ticket draw and Joker board (a lottery style game involving a deck of playing cards). Although regulations prohibit Clubs from promoting EGMs at their venues (NSW Government, 2001), five Clubs (8\%) communicated the presence of EGMs at the Club by including photos on their websites in which EGMs were clearly visible or by referring to EGMs at the venue through text or by offering to send individuals information about EGMs directly if an email address was provided.

Qualitative interpretation of marketing relating to gambling products and services presented on the websites resulted in three themes. The first theme to emerge was the emphasis on 
better value and increased chances associated with gambling activities, for example: a "lucky winner” in gambling. Taglines included "there’s more choice, chance and value”, "want a chance to win some extra cash?” and "every spinner is guaranteed to walk away with at least $\$ 50$ in prizes”. The second theme related to the way in which gambling activities could be utilised to ease financial strains through cash prizes. This was represented using a variety of activities where members were given the "chance to cover the cost of their household expenses" and promotions such as "billbusters" and "burn the bill”. The third theme related to the facilities of the Club and how these created a positive and comfortable experience for gamblers. For example, “a comfortable sports bar with all the facilities for the punter”, “quality furnishings for your comfort” and "state of the art TAB facilities”.

\section{Discussion and Conclusion}

This study aimed to investigate the nature and extent to which family-friendly activities are promoted for venues that also offer gambling activities. We did this by examining the information provided relating to family activities within Club websites that also promote gambling activities. While this study is relatively small and looks at these forms of promotions only in the context of website marketing, it provides important information to guide future studies exploring how non-gambling activities may impact on the attitudes of children and families towards environments that also contain gambling activities and promotions, as well as short- and long-term gambling consumption intentions. Findings from this study show that child- and family-based activities are being offered and promoted within venues that also offer a range of gambling activities available exclusively to adults. 
Three key points emerged for discussion. First, gambling venues in this study were predominantly located in low socio-economic areas, a finding that is consistent with trends reported in both the Australian (Young et al., 2012a; McMillen \& Doran, 2006) and international literature (Pearce, Mason, Hiscock, \& Day, 2008; Wheeler, Rigby, \& Huriwai, 2006). This poses a significant challenge for public health authorities given the harms associated with gambling for vulnerable populations, including those from low socioeconomic backgrounds (Welte, Wieczorek, Barnes, Tidwell, \& Hoffman, 2004; Welte, Wieczorek, Barnes, \& Tidwell, 2006). Researchers have proposed that the cluster of EGM venues in low socio-economic areas is due to industry's pursuit to increase profits (EGM expenditure) (Livingstone, 2001; Marshall \& Baker, 2001), future research is required to explore this further. As seen in other areas of health, for example the normalisation of drug use (Parker, Williams, \& Aldridge, 2002), increased availability and accessibility constitutes an important dimension of normalisation. In this context, high availability and accessibility of gambling venues in vulnerable areas may act to normalise both the venue and gambling for the communities in which they are located. We hypothesise that normalisation of gambling and the promotion of such venues as 'family friendly' places may increase the risk of gambling harm within these communities, particularly amongst adults who are exposed to gambling venues as children. This is an important area for future research. The density of Clubs in areas of low socio-economic status also suggests that policy consideration should be given to regulating the number of Clubs permitted to operate in specific geographical areas. We agree with other authors that the absence of such comprehensive reform may inevitably lead to the perpetuation of gambling harm in our poorest communities (Markham \& Young, 2014; Rintoul, Livingstone, Mellor, \& Jolley, 2012). 
Second, there is a clear juxtaposition between the provision of, and reliance on, adults-only gambling products and services and the provision and promotion of family-friendly and children-focused activities within the same environments. There is no doubt that Clubs provide services, particularly in regional areas, that fill a gap in activities and services for children and their families. However, we hypothesise that problems may arise when these activities are either co-located in venues which also offer gambling activities or are subsidised by gambling activities. Public health frameworks recognise the role of the (immediate) environment in stimulating the short- and long-term behaviours related to the consumption of products that may be harmful for individuals and communities (Frieden, 2010). For example, significant research has explored how marketing and environmental factors may work together to stimulate the consumption of alcohol and tobacco (ANPHA, 2014; Collins, Ellickson, McCaffrey, \& Hambarsoomians, 2007; Difranza et al., 1991). Recent research also illustrates that marketing is used effectively to normalise gambling through the alignment of sports betting with sport (Thomas, 2014; Lindsay et al., 2013; Thomas, Lewis, McLeod, \& Haycock, 2012).

Gambling research has highlighted the influential role of gambling marketing on children's perceptions of gambling and engagement in gambling activities (McMullan, Miller, \& Perrier, 2012; Thomas, 2014). Researchers have argued that marketing initiatives that shape environments to cue certain behaviours are extremely effective, often to the detriment of health (Sepe, Ling, \& Glantz, 2002). This suggests that the recent proposal by Clubs NSW to provide childcare services (McKell Institute, 2014) may have an undesirable impact on young children if the services are provided in environments that also contain addictive activities such as gambling. Clubs state that they are at the "heart of every community" (Clubs NSW, 2015) and are "local community organisations, (that) are highly responsive in addressing the 
needs of their members, guests and the broader community” (Clubs Australia, 2015b). We hypothesise that children's exposure to gambling venues from a young age through exposure to these organisations may result in future gambling harm, even if children are not directly exposed to the gambling product (e.g. do not directly come into contact with EGMs). Further research should include a public health based approach that examines a range of social and environmental factors (Messerlian \& Derevensky, 2005) to explore whether marketing that promotes family attendance at venues, which also contains gambling products and services, has a short- or long-term effect on children's future attitudes towards these venues, and subsequent consumption of gambling products.

Third, based on the study results, we propose a model of shaping strategies as one way of understanding how the marketing strategies that venues use may be intentionally or unintentionally normalising gambling environments for children and families (igure 1). The present study has shown that a range of promotional strategies are used to attract families and children into venues. The prominent presence of child- and family-related promotions on home pages is indicative of the importance of this target group for these venues. The frequent use of images of children suggests that these are places where children 'belong' and are welcome. While there are regulations that aim to prevent children from coming into direct contact with more harmful forms of gambling (such as EGMs) (NSW Government 1976), the marketing strategies identified here may increase the likelihood that the venues will be normalised among children as positive environments, resulting in higher rates of patronage in adulthood. If this is the case, it also seems likely that children who regularly attend these venues may transition more seamlessly into the range of gambling activities that are offered within that environment. This may be particularly so in areas where there is an absence of other forms of activity or entertainment. Many 'family friendly' activities are seemingly 
embed the Clubs as a part of regular family rituals, for example birthdays, Mother's day, school holiday programs and weekly meals. This reinforces the community perception that Clubs are a suitable environment for children (cheap meals, local, family friendly). Figure 1 proposes a conceptual model using the concept of 'shaping', which may partly explain how exposure to gambling venues may ultimately leads to engagement in gambling. Future research should aim to test this model and investigate the attitudes, consumption patterns and future consumption intentions of both children and parents who attend Club venues to understand how children perceive gambling and gambling venues. 


\section{REFERENCES}

Armstrong, D., Gosling, A., Weinman, J., \& Marteau, T. (1997). The place of inter-rater reliability in qualitative research: an empirical study. Sociology, 31(3), 597-606. doi: 10.1177/0038038597031003015

Australian Bureau of Statistics (ABS). (2013). Census of Population and Housing: SocioEconomic Indexes for Areas (SEIFA), Australia, 2011 Retrieved 1 April 2015, from http://www.abs.gov.au/ausstats/abs@.nsf/DetailsPage/2033.0.55.0012011?OpenDocu ment

Australian Productivity Commission. (1999). Australia's Gambling Industries Volume 1: (Parts A-C). Canberra: Australian Productivity Commission.

Australian Productivity Commission. (2010). Inquiry Report into Gambling. Canberra: Australian Productivity Commission.

Australian National Preventive Health Agency (ANPHA). (2014). Alcohol advertising: The effectiveness of Current Regulatory Codes in Addressing Community Concern. Draft Report February

Blaszczynski, A., Ladouceur, R., \& Shaffer, H. J. (2004). A Science-Based Framework for Responsible Gambling: The Reno Model. Journal of Gambling Studies, 20(3), 301317.

Clubs Australia. (2015a). Partofthesolution.com.au: About Us. Retrieved 1 April 2015, from http://www.partofthesolution.com.au/about-us

Clubs Australia. (2015b). About Clubs. Retrieved 1 April 2015, from http://www.clubsaustralia.com.au/about-us/club-industry

Clubs NSW. (2015). About the Clubs Industry. Retrieved 1 April, 2015, from http://www.clubsnsw.com.au/our-industry/the-club-industry/about-the-club-industry

Collins, R. L., Ellickson, P. L., McCaffrey, D., \& Hambarsoomians, K. (2007). Early Adolescent Exposure to Alcohol Advertising and Its Relationship to Underage Drinking. Journal of Adolescent Health, 40(6), 527-534.

deCastella, A., Bolding, P., Lee, A., Cosic, S., \& Kulkarni, J. (2011). Problem gambling in young people presenting to a public mental health service. Melbourne, Victoria: Office of Gambling and Racing, Department of Justice.

Difranza, J. R., Richards, J. W., Paulman, P. M., Wolfgillespie, N., Fletcher, C., Jaffe, R. D., \& Murray, D. (1991). Rjr nabiscos cartoon camel promotes camel cigarettes to children. Journal Of The American Medical Association, 266(22), 3149-3153.

Doran, B. J., McMillen, J., \& Marshall, D. C. (2007). A GIS-based Investigation of Gaming Venue Catchments. Transactions in GIS, 11(4), 575-595. doi: 10.1111/j.14679671.2007.01061.X

Dow-Schüll, N. (2012). Addiction by Design: Machine Gambling in Las Vegas. Princeton United States: Princeton University Press.

The Economist. (2014). The House Wins: Who Gambles the Most? Retrieved 10th October, 2014, from http://www.economist.com/blogs/graphicdetail/2014/02/daily-chart-0

Frieden, T. R. (2010). A Framework for Public Health Action: The Health Impact Pyramid. American Journal of Public Health, 100(4), 590-595.

Gaming Technologies Australia. (2015). Responsible Gaming Machine Play. Retrieved 1 April, 2015, from http://gamingta.com/pdf/responsible_gaming_machine_play.pdf

Glaser, B. G., \& Strauss, A. L. (1967). The discovery of grounded theory: Strategies for qualitative research. Chicago: Aldine-Atherton. 
Halford, J. C. G., Gillespie, J., Brown, V., Pontin, E. E., \& Dovey, T. M. (2004). Effect of television advertisements for foods on food consumption in children. Appetite, 42(2), 221-225.

Hammond, R., \& Rowell, A. (2001). Trust Us: We're The Tobacco Industry. Campaign for Tobacco Free Kids and ASH (UK), Washington and London. . Retrieved 1 April, 2015, from http://www.ash.org.uk/files/documents/ASH_135.pdf

Hing, N. (2006). A History of Machine Gambling in the NSW Club Industry: From Community Benefit to Commercialisation. International Journal of Hospitality \& Tourism Administration, 7(2), 83-107.

Holdsworth, L., Haw, J., \& Hing, N. (2012). The Temporal Sequencing of Problem Gambling and Comorbid Disorders. International Journal Of Mental Health And Addiction, 10(2), 197-209.

Kalischuk, R. G. (2010). Cocreating life pathways: Problem gambling and its impact on families. The Family Journal, 18(1), 7-17.

Kalischuk, R. G., Nowatzki, N., Cardwell, K., Klein, K., \& Solowoniuk, J. (2009). Once a gambler - always a gambler? A longitudinal analysis of gambling patterns in young people making the transition from adolescence to adulthood. International Gambling Studies, 9(2), 151-163.

Lindsay, S., Thomas, S., Lewis, S., Westberg, K., Moodie, R., \& Jones, S. (2013). Eat, drink and gamble: marketing messages about 'risky'products in an Australian major sporting series. BMC public health, 13(719).

Ling, P. M., \& Glantz, S. A. (2002). Why and How the Tobacco Industry Sells Cigarettes to Young Adults: Evidence From Industry Documents. American Journal of Public Health, 92(6), 908-916.

Livingstone, C. (2001). The social economy of poker machine gambling in Victoria. International Gambling Studies, 1(1), 46-65.

Lorains, F. K., Cowlishaw, S., \& Thomas, S. A. (2011). Prevalence of comorbid disorders in problem and pathological gambling: systematic review and meta-analysis of population surveys. Addiction, 106(3), 490-498.

Markham, F., \& Young, M. (2015). "Big Gambling”: The rise of the global industry-state gambling complex. Addiction Research \& Theory 23(1), 1-4.

Marshall, D., \& Baker, R. (2001). Unfair odds? Factors influencing the distribution of electronic gaming machines in Melbourne. Urban policy and research, 19(1), 77-92.

Martin, K. D., \& Smith, N. C. (2008). Commercializing social interaction: The ethics of stealth marketing. Journal of Public Policy \& Marketing, 27(1), 45-56.

McCracken, G. (1986). Culture and consumption: A theoretical account of the structure and movement of the cultural meaning of consumer goods. Journal of Consumer Research, 71-84.

The McKell Institute. (2014). Meeting The Shortfall: How Clubs can provide affordable social services in our communities. Retrived from http://mckellinstitute.org.au/wpcontent/uploads/2014/05/McKell-Institute-Meeting-The-Shortfall.pdf

McMillen, J., \& Doran, B. (2006). Problem gambling and gaming machine density: Sociospatial analysis of three Victorian localities. International Gambling Studies, 6(1), 529.

McMullan, J. L., Miller, D. E., \& Perrier, D. C. (2012). “I’ve Seen Them So Much They Are Just There”: Exploring Young People's Perceptions of Gambling in Advertising. International journal of mental health and addiction, 10(6), 829-848.

Messerlian, C., \& Derevensky, J. L. (2005). Youth gambling: A public health perspective. Journal of Gambling Issues. 
Miles, M., \& Huberman, A. (1994). Qualitative Data Analysis: An Expanded Sourcebook.: Thousand Oaks, Sage Publications.

Miller, H. E., Thomas, S. L., Robinson, P., \& Daube, M. (2014). How the causes, consequences and solutions for problem gambling are reported in Australian newspapers: a qualitative content analysis. Australian and New Zealand journal of public health, 38(6), 529-535.

Neal, P., Delfabbro, P., \& O’Neil, M. (2005). Problem Gambling and Harm: Towards a National Definition. Melbourne: State of Victoria Department of Justice.

Needham, K. (2014). Punters in west pile money in pokies. The Sydney Morning Herald. Retrieved from http://www.smh.com.au/nsw/punters-in-west-pile-money-in-pokies20140322-35a2h.html

Nord, W. R., \& Peter, J. P. (1980). A Behavior Modification Perspective on Marketing. Journal of Marketing, 44(2), 36-47.

Nowell, L. (2009). Pokie venues are 'fun palaces'. Herald Sun. Retrieved from http://www.heraldsun.com.au/news/victoria/pokie-venues-are-fun-palaces/storye6frf7kx-1225804953814

NSW Government, 2001, GAMING MACHINES ACT 2001-Section 43, (NSW). Available from http://www5.austlii.edu.au/au/legis/nsw/consol_act/gma2001130/s43.html

Otnes, C., \& Scott, L. M. (1996). Something old, something new: exploring the interaction between ritual and advertising. Journal of Advertising, 25(1), 33-50.

Parker, H., Williams, L., \& Aldridge, J. (2002). The Normalization of 'Sensible'Recreational Drug Use Further Evidence from the North West England Longitudinal Study. Sociology, 36(4), 941-964.

Pearce, J., Mason, K., Hiscock, R., \& Day, P. (2008). A national study of neighbourhood access to gambling opportunities and individual gambling behaviour. Journal of Epidemiology and Community Health (1979-), 62(10), 862-868.

Peter, J. P., \& Nord, W. R. (1982). A Clarification and Extension of Operant Conditioning Principles in Marketing. Journal of Marketing, 46(3), 102-107.

Rintoul, A. C., Livingstone, C., Mellor, A. P., \& Jolley, D. (2012). Modelling vulnerability to gambling related harm: How disadvantage predicts gambling losses. Addiction Research \& Theory, 21(4), 329-338.

Robitaille, É., \& Herjean, P. (2008). An analysis of the accessibility of video lottery terminals: The case of Montréal. International Journal of Health Geographics, 7(1), $2-2$.

Rossiter, J. R. (2011). Measurement for the social sciences: the C-OAR-SE method and why it must replace psychometrics. New York: Springer.

Rothschild, M. L., \& Gaidis, W. C. (1981). Behavioral learning theory: its relevance to marketing and promotions. The Journal of Marketing, 70-78.

Roy Morgan. (2014). Gambling Monitor: Most of Australia's gambling dollars are spent on pokies. Retrieved 1 April, 2015, from http://www.roymorgan.com/findings/5627most-of-australias-gambling-dollars-spent-on-pokies-201406060048

Salonen, A. H., Castrén, S., Alho, H., \& Lahti, T. (2014). Concerned significant others of people with gambling problems in Finland: a cross-sectional population study. BMC public health, 14(1), 398.

Sepe, E., Ling, P. M., \& Glantz, S. A. (2002). Smooth Moves: Bar and Nightclub Tobacco Promotions That Target Young Adults. American Journal of Public Health, 92(3), 414-419.

Sherry, J. F. (1987). Advertising as a cultural system. Marketing and semiotics: New directions in the study of signs for sale, 441-461. 
Smith, L. A., \& Foxcroft, D. R. (2009). The effect of alcohol advertising, marketing and portrayal on drinking behaviour in young people: Systematic review of prospective cohort studies. BMC public health, 9(1), 51-51.

Storer, J., Abbott, M., \& Stubbs, J. (2009). Access or adaptation? A meta-analysis of surveys of problem gambling prevalence in Australia and New Zealand with respect to concentration of electronic gaming machines. International Gambling Studies, 9(3), 225-244.

Svensson, J., Romild, U., \& Shepherdson, E. (2013). The concerned significant others of people with gambling problems in a national representative sample in Sweden-a 1 year follow-up study. BMC public health, 13(1), 1087.

Suomi, A., Koziol-McLain, J., Cockman, S., Jackson, A. C., Dowling, N. A., Lavis, T., . . Bellringer, M. E. (2013). Problem gambling and family violence: family member reports of prevalence, family impacts and family coping. Asian Journal of Gambling Issues and Public Health, 3(1), 1-15.

Thomas, S. L., Lewis, S., McLeod, C., \& Haycock, J. (2012). 'They are working every angle'. A qualitative study of Australian adults' attitudes towards, and interactions with, gambling industry marketing strategies. International Gambling Studies, 12(1), 111127.

Thomas, S. L. (2014). Parents and adolescents discuss gambling advertising: a qualitative study. Victoria, Australia: Victorian Responsible Gambling Foundation.

Walters, G. D. (1997). Problem Gambling in a Federal Prison Population: Results from the South Oaks Gambling Screen. Journal of Gambling Studies, 13(1), 7-24.

Webster, C. M., Carter, L. M., D'Alessandro, S., \& Gray, D. (2013). Social marketing: good Intentions. Prahan, VIC: Tilde University Press.

Welte, J. W., Wieczorek, W. F., Barnes, G. M., Tidwell, M.-C., \& Hoffman, J. H. (2004). The Relationship of Ecological and Geographic Factors to Gambling Behavior and Pathology. Journal of Gambling Studies, 20(4), 405-423.

Welte, J. W., Wieczorek, W. F., Barnes, G. M., \& Tidwell, M. C. O. (2006). Multiple Risk Factors for Frequent and Problem Gambling: Individual, Social, and Ecological. Journal of Applied Social Psychology, 36(6), 1548-1568.

Wenzel, H. G., Øren, A., \& Bakken, I. J. (2008). Gambling problems in the family-A stratified probability sample study of prevalence and reported consequences. BMC public health, 8(1), 412.

Wheeler, B. W., Rigby, J. E., \& Huriwai, T. (2006). Pokies and poverty: problem gambling risk factor geography in New Zealand. Health and Place, 12(1), 86-96.

Young, M., Markham, F., \& Doran, B. (2012a). Placing Bets: gambling venues and the distribution of harm. Australian Geographer, 43(4), 425-444.

Young, M., Markham, F., \& Doran, B. (2012b). Too close to home? The relationships between residential distance to venue and gambling outcomes. International Gambling Studies, 12(2), 257-273. 
Table 1: Coding Categories

\begin{tabular}{|c|c|}
\hline Website marketing content & Definition \\
\hline \multicolumn{2}{|l|}{ Families and children } \\
\hline $\begin{array}{l}\text { Direct calls to bring the family } \\
\text { to the Club }\end{array}$ & - Encouragement to visit the Club with the family. \\
\hline Children’s dining & $\begin{array}{l}\text { - Meals specifically designed and priced for children. } \\
\text { - Promotions in which children eat free. }\end{array}$ \\
\hline Children's activities & $\begin{array}{l}\text { - } \text { Events for under } 18 \text { year olds (e.g. Kids’ Discos). } \\
\text { - } \quad \text { Play equipment for children. } \\
\text { - Supervised or organised activities or spaces for } \\
\text { children, e.g. colouring in or craft sessions, or games } \\
\text { rooms. }\end{array}$ \\
\hline Holiday promotions & $\begin{array}{l}\text { - Seasonal promotions associated with ritualistic and } \\
\text { cultural celebrations, e.g. Christmas, Easter and } \\
\text { Mother's Day. } \\
\text { - Program of activities promoted as school holiday } \\
\text { fun for children. }\end{array}$ \\
\hline Child minding & $\begin{array}{l}\text { - Facilities for supervision of children under the age } \\
\text { of } 18 .\end{array}$ \\
\hline Family days & $\begin{array}{l}\text { - Specific days labelled as “family days” with } \\
\text { activities for families, e.g. BBQs, face painting and } \\
\text { jumping castles. }\end{array}$ \\
\hline Family major promotion & $\begin{array}{l}\text { - Major competitions or prizes designed for the } \\
\text { family, e.g. Family holiday prize draws for two } \\
\text { adults and two children. }\end{array}$ \\
\hline Other & $\begin{array}{l}\text { - Any activities that did not fit into the above, such as } \\
\text { computer equipment for hire, promotion of extended } \\
\text { children's hours and mini golf. }\end{array}$ \\
\hline \multicolumn{2}{|r|}{ 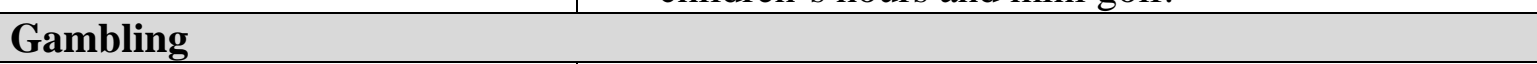 } \\
\hline Electronic Gaming Machines & $\begin{array}{l}\text { Gambling machines with a number of (electronic) reels } \\
\text { that spin when a button is pushed, and pay (or don't } \\
\text { pay) the player money depending on the combination of } \\
\text { symbols displayed after reels stop spinning. }\end{array}$ \\
\hline Dedicated gaming area & $\begin{array}{l}\text { Area of the Club dedicated to gaming (gambling) } \\
\text { activities, which may be inside or outside the Club (to } \\
\text { allow people to smoke while playing). }\end{array}$ \\
\hline Keno & $\begin{array}{l}\text { A bingo-style game of chance that involves drawing out } \\
\text { numbers and covering of corresponding numbers on } \\
\text { printed cards. }\end{array}$ \\
\hline TAB & $\begin{array}{l}\text { Electronic betting facility that enables bets to be placed } \\
\text { on a range of national and international sporting and } \\
\text { racing events. }\end{array}$ \\
\hline Cash poker & Poker tournaments played with cash prizes. \\
\hline Raffles & $\begin{array}{l}\text { A sweepstake in which numbered tickets are drawn at } \\
\text { random and the corresponding ticket holder wins a } \\
\text { prize. }\end{array}$ \\
\hline Other forms of gambling & $\begin{array}{l}\text { Activities whereby participants partake in a game of } \\
\text { chance with the result of winning prizes, points or }\end{array}$ \\
\hline
\end{tabular}




\begin{tabular}{|l|l|}
\hline & money. Usually a game created specifically for that \\
Club to increase participation or increase involvement in \\
more generic gambling options (e.g. "losing TAB \\
ticket” requires a person to place a bet at the TAB, and \\
if they don't win their losing ticket goes into another \\
prize draw. This gives the illusion that the individual has \\
a better chance of winning something if they place the \\
initial bet.
\end{tabular}


Table 2: Sample characteristics

\begin{tabular}{|c|c|}
\hline CLUB DESCRIPTION & N (valid \%) \\
\hline \multicolumn{2}{|l|}{ Club type } \\
\hline Bowling & $25(39)$ \\
\hline Returned Servicemen’s League (RSL) & $11(17)$ \\
\hline Football & $8(12)$ \\
\hline Golf & $5(8)$ \\
\hline Sports & $4(6)$ \\
\hline Other & $12(19)$ \\
\hline \multicolumn{2}{|l|}{ Geographic location - SEIFA decile } \\
\hline $1-3$ & $39(60)$ \\
\hline $4-7$ & $17(26)$ \\
\hline $8-10$ & $9(14)$ \\
\hline Total & $65(100)$ \\
\hline CLUB SIZE $^{\dagger}$ & N (actual \%) \\
\hline \multicolumn{2}{|l|}{ Membership } \\
\hline Under 1,000 & $3(6)$ \\
\hline $1,001-5,000$ & $17(35)$ \\
\hline $5,001-10,000$ & $5(10)$ \\
\hline $10,001+$ & $7(14)$ \\
\hline Information not provided in report & $17(35)$ \\
\hline \multicolumn{2}{|l|}{ Gross EGM revenue* } \\
\hline $0-\$ 1,000,000$ & $16(33)$ \\
\hline$\$ 1,000,001-\$ 5,000,000$ & $15(31)$ \\
\hline$\$ 5,000,001-\$ 10,000,000$ & 9 (18) \\
\hline$\$ 10,000,001+$ & $6(12)$ \\
\hline Information not provided in report & $3(6)$ \\
\hline TOTAL & $49(100)$ \\
\hline
\end{tabular}

${ }^{\dagger}$ Actual and percentage figures reported for the 49 Clubs for which annual reports were available

* Revenue for most recently reported 12 month period 
Table 3: Club webpage marketing directed at families and children co-located on webpages containing gambling marketing

\begin{tabular}{|l|c|c|c|}
\hline & $\begin{array}{c}\text { Home page } \\
\text { N (\%) }\end{array}$ & $\begin{array}{c}\text { Secondary } \\
\text { pages } \\
\text { N (\%) }\end{array}$ & $\begin{array}{c}\text { TOTAL } \\
\text { N (\%) }\end{array}$ \\
\hline Families and children & \multicolumn{2}{|l|}{} \\
\hline Children's dining & $45(69)$ & $45(69)$ \\
\hline $\begin{array}{l}\text { Direct calls to bring the family to the } \\
\text { Club }\end{array}$ & $6(9)$ & $18(28)$ & $22(34)$ \\
\hline Children's activities & $3(5)$ & $14(22)$ & $14(22)$ \\
\hline Holiday promotions & $1(2)$ & $9(14)$ & $9(14)$ \\
\hline Child minding & $1(2)$ & $6(9)$ & $6(9)$ \\
\hline Family days & $0(0)$ & $4(6)$ & $4(6)$ \\
\hline Family major promotion & $0(0)$ & $3(5)$ & $3(5)$ \\
\hline Other & $2(3)$ & $11(17)$ & $12(19)$ \\
\hline TOTAL & $\mathbf{1 3 ( 2 0 )}$ & $\mathbf{5 6 ( 8 6 )}$ & $\mathbf{5 6}(\mathbf{8 6})$ \\
\hline Gambling & $30(46)$ & $51(79)$ & $56(86)$ \\
\hline Raffles & $17(26)$ & $44(68)$ & $48(74)$ \\
\hline TAB & $16(25)$ & $36(55)$ & $43(66)$ \\
\hline Keno & $8(12)$ & $26(40)$ & $27(42)$ \\
\hline Cash poker & $4(6)$ & $9(14)$ & $12(19)$ \\
\hline Dedicated gaming area & $0(0)$ & $5(8)$ & $3(5)$ \\
\hline Electronic gaming machines & $8(12)$ & $22(34)$ & $22(34)$ \\
\hline Other forms of gambling & $\mathbf{4 0 ( 6 2 )}$ & $\mathbf{6 1 ( 9 4 )}$ & $\mathbf{6 2 ( 9 5 )}$ \\
\hline TOTAL &
\end{tabular}

${ }^{1}$ Values do not add to $100 \%$ because some Clubs may include more than one type of marketing strategy on their website. 
Figure 1

Shaping pathways to venue based gambling: A conceptual model

\begin{tabular}{|c|c|c|c|}
\hline Step 1 & Step 2 & Step 3 & Step 4 \\
\hline $\begin{array}{l}\text { Extent and nature } \\
\text { of marketing } \\
\text { targeting children } \\
\text { and families }\end{array}$ & $\begin{array}{l}\text { Creating rituals } \\
\text { and norms, } \\
\text { familiarity and } \\
\text { preference }\end{array}$ & $\begin{array}{c}\text { Normalisation of } \\
\text { the Club } \\
\text { environment as } \\
\text { cultural and } \\
\text { social setting }\end{array}$ & $\begin{array}{l}\text { Normalisation of } \\
\text { the Club's } \\
\text { gambling } \\
\text { environment }\end{array}$ \\
\hline $\begin{array}{l}\text {-Children's dining } \\
\text { - Children's } \\
\text { activities } \\
\text { - Holiday } \\
\text { promotions } \\
\text { - Direct calls to } \\
\text { bring the family to } \\
\text { the club } \\
\text { - Child minding } \\
\text { - Family days } \\
\text { - Family major } \\
\text { promotions }\end{array}$ & $\begin{array}{l}\text { - Family dinners } \\
\text { - Celebrations } \\
\text { - Loyalty programs } \\
\text { - Repeat behaviours } \\
\text { - Positive } \\
\text { experiences }\end{array}$ & $\begin{array}{l}\text {-Club is accepted } \\
\text { as positive part of } \\
\text { Australian life }\end{array}$ & $\begin{array}{l}\text {-Increased } \\
\text { likelihood of } \\
\text { gambling as adults }\end{array}$ \\
\hline
\end{tabular}

